\title{
Ação Mediada e Ensino por Investigação: Um Estudo Junto a Alunos do Ensino Médio em um Museu de Ciências
}

\section{Mediated Action and Inquiry-Based Leaning: A Study with high School Students at a Science Museum}

\author{
Maria Margareth Cancian Roldi \\ Brasil \\ Mirian do Amaral Jonis Silva \\ Brasil \\ Patricia Silveira da Silva Trazzi \\ Brasil
}

Este artigo tem como objetivo analisar a mediação realizada em um museu de ciências durante uma atividade investigativa desenvolvida junto com um grupo de dez alunos de ensino médio de uma escola pública. A matriz teórica e metodológica foi a históricocultural e inspiradas na abordagem do ensino por investigação e na ação mediada. A pesquisa teve cunho qualitativo e colaborativo uma vez que uma professora de biologia e um pesquisador do museu de ciências trabalharam em parceria na elaboração de um roteiro investigativo que foi desenvolvido junto a um grupo de estudantes como parte de uma das ações do programa educativo do museu sobre a temática "répteis". Os dados foram produzidos por meio de gravação de áudio e anotações em diário de campo durante o desenvolvimento da atividade. Para fins de análise, os dados foram selecionados e organizados em episódios que foram categorizados de acordo com os pressupostos do ensino por investigação: problematização e levantamento de hipóteses, teste de hipóteses e sistematização do conhecimento. As análises apontaram que durante o desenvolvimento da ação mediada, no contexto do museu de ciências, os alunos puderam vivenciar uma investigação científica participando ativamente do processo de construção do conhecimento. Evidencia-se aqui a importância de uma mediação pedagógica qualificada no decorrer da atividade investigativa, ressaltando-se a ação dos agentes operando com as ferramentas culturais disponíveis que contribuíram para potencializar o processo de aprendizagem dos conceitos biológicos abordados.

Palavras-chave: Ensino por Investigação; Mediação; Educação não Formal; Museu de Ciências.

This work aims to analyze the mediation carried out in a science museum during an investigative activity developed together with a group of ten high school students from a public school. The theoretical and methodological matrix was historical-cultural and inspired by the Inquiry-Based Learning and Mediated Action approaches. The research was qualitative and collaborative, as for a biology teacher and a researcher from the science museum worked in partnership in the elaboration of an investigative script that 
was developed with a group of students as part of one of the actions of the museum's educational program on the theme of "reptiles". The data were produced by means of audio recording and field journal annotations during the development of the activity. For the purpose of analysis, the data were selected and organized into episodes that were categorized according to the stages of Inquiry-Based Learning: problematization and hypothesis collection, hypothesis testing and knowledge systematization. The analysis showed that during the development of mediated action, in the context of the museum of sciences, students were able to experience the stages of a scientific investigation by actively participating in the process of knowledge construction. It is evident that a qualified pedagogical mediation in the course of the research activity is fundamental, focusing on the action of the agents operating with the available cultural tools that contributed to enhance the learning process of the biological concepts approached.

Keywords: Inquiry-Based Learning; Mediation; Non-Formal Education; Museum of Sciences.

\section{Introdução}

Este artigo tem como objetivo analisar a mediação realizada em um museu de ciências, o Instituto Nacional da Mata Atlântica, durante uma atividade investigativa desenvolvida junto com um grupo de alunos de ensino médio de uma escola pública estadual do Espírito Santo. A intenção foi caracterizar e problematizar a atividade proposta pelo museu na sua relação com a Escola. A atividade analisada trata de uma etapa de um projeto educativo realizado no museu na sua edição sobre "répteis".

Nossa matriz teórica se baseia na perspectiva histórico-cultural, especificamente na ação mediada de James Wertsch $(1991,1998,1999)$ e na vertente do Ensino de Ciências por Investigação defendida por autores como Azevedo (2009); Capecchi, (2013); Carvalho, (2009); Carvalho, (2013); Gil-Perez (1986); Gil-Perez e Carvalho, (2000); Munford e Lima, (2007); Sá, Lima e Aguiar Junior (2011). Wertsch (1998), a partir dos estudos de Vygotsky sobre mediação e da ideia de enunciado como forma de ação (Bakhtin, 2009), nos diz que todo ato realizado pelo ser humano pressupõe uma ação mediada e que esta ação humana serve como objeto fundamental para ser descrito e interpretado.

O conceito de mediação na teoria sociocultural de Vygotsky diz respeito a como os seres humanos agem e interagem com diferentes ferramentas culturais ou artefatos mediadores. Segundo Wertsch (1999), estas ferramentas culturais podem ser tanto psicológicas (pensamentos) ou técnicas (computadores, etc.) e podem ser usadas para explorar como os seres humanos agem mediando ferramentas culturais em suas vidas cotidianas e situações de aprendizagem.

Burke (1969) citado em Wertsch (1999) apresenta cinco elementos da ação mediada: ato, cena, agente, agência e propósito. $\mathrm{O}$ ato seria o que acontece na ação ou no pensamento; a cena refere-se à situação na qual ocorreu a ação; o agente é aquele que 
realiza a ação; o propósito refere-se à intenção que o agente teve ao realizar a ação; e a agência são as ferramentas culturais ou instrumentos utilizados para aquele fim. Para Wertsch (1999), a ação mediada centra-se inicialmente nos agentes e suas ferramentas culturais, mediadoras da ação, o que significa que o foco é na interação dos agentes que operam com as ferramentas culturais. Isso pressupõe uma atenção especial aos sistemas, valores e códigos utilizados pelos agentes, pois as ferramentas culturais estão imbricadas ao contexto social e histórico dos envolvidos no processo de mediação.

Ao abordarmos a ação mediada no contexto de um museu de ciências, utilizando a perspectiva do ensino de ciências por investigação, estamos falando de uma forma de ação mediada que é diferente de uma implementada em uma escola, por exemplo, porque o contexto de realização da atividade é outro. O ensino de ciências por investigação, geralmente é desenvolvido em espaços de educação formal contando com várias propostas pedagógicas que utilizam a investigação como foco principal para ensinar ciências. No entanto, defendemos que o ensino de ciências por investigação pode ser utilizado em espaços de educação não formal como os museus de ciências. Tais espaços geralmente possuem diversos recursos como exposições e laboratórios que podem ser utilizados como ferramentas para a implementação de atividades investigativas.

Segundo Carvalho (2017) os museus são considerados como espaço de educação não formal, ou seja, como tendo qualquer atividade organizada fora do sistema formal de educação, operando separadamente ou como parte de uma atividade mais ampla, com objetivos educacionais.

Do ponto de vista da aprendizagem, Carvalho (2017) nos diz que os museus podem ser classificados como:

(i) Espaços de educação não formal: quando ele, como instituição, tem um projeto de alguma forma estruturado e com um determinado conteúdo programático; (ii) Espaços de educação formal: quando os alunos o visitam com uma atividade totalmente estruturada por sua escola, buscando aperfeiçoamento em determinado conteúdo conceitual. Nesse caso, o museu é observado não como instituição, mas pelo ponto de vista de seu público; (iii) Espaços de educação informal: quando um visitante o procura para se divertir ou um turista quer conhece-lo. Também nesse caso o museu é observado não como instituição, mas pelo ponto de vista de seu público (Carvalho, 2017, p. 99).

No caso desta pesquisa, o museu de ciências é tratado sob o ponto de vista da aprendizagem como um espaço de educação não formal, visto que, como instituição, tem um projeto estruturado que visa receber estudantes da educação básica com a finalidade de desenvolver determinados conteúdos programáticos da área de biologia. Assim, buscamos a complementaridade desse tipo de espaço com uma escola da rede pública da região. Esta interação, museu e escola, revela-se frutífera segundo Carvalho (2017), à medida que o ensino pode adquirir contornos específicos no que se refere à construção de conhecimentos pelos alunos.

Wertsch (1999) traz a visão de que toda ação humana é uma ação mediada e por isso considera muito difícil fornecer uma lista das formas de ação e das ferramentas 
culturais que a caracterizam. Assim, o autor fornece um conjunto de afirmações básicas que caracterizam a ação mediada e as ferramentas culturais: 1) a ação mediada se caracteriza por uma tensão irredutível entre o agente e as ferramentas culturais, ou seja, o agente é o indivíduo que opera com as ferramentas culturais de forma indissociável porque os elementos que compõem a ação mediada estão sempre interagindo e se combinando. Assim, o uso dessas ferramentas só é possível se há um sujeito que saiba operar com elas; 2) as ferramentas culturais são materiais, ou seja, a materialidade é uma propriedade de qualquer ferramenta cultural (tanto objetos quanto as palavras, inclusive quando expressas em linguagem falada). $\mathrm{O}$ uso de objetos materiais como ferramentas culturais resulta em mudanças no agente; 3) a ação mediada, em geral, tem múltiplos objetivos simultâneos; 4) a ação mediada se situa em um ou mais caminhos evolutivos, ou seja, está historicamente situada; 5) as ferramentas culturais restringem, e, ao mesmo tempo, possibilitam a ação; 6) as ferramentas culturais transformam a ação mediada, ou seja, a introdução de novas ferramentas culturais pode transformar a ação e pode proporcionar o contexto para se avaliar as habilidades do agente operando com uma ferramenta cultural específica; 7) a relação dos agentes com as ferramentas culturais pode caracterizar-se, do ponto de vista do domínio, ou seja, com o saber como usar uma ferramenta cultural; 8) a relação dos agentes com as ferramentas culturais pode caracterizar-se do ponto de vista da apropriação, ou seja, tomar algo que pertence a outro e torná-lo próprio; 9) as ferramentas culturais são produzidas por motivos alheios à facilitação da ação mediada, ou seja, são, muitas vezes, utilizadas com finalidades diferentes daquelas para as quais foram originalmente pensadas ou produzidas; 10) as ferramentas culturais se associam com o poder e com a autoridade.

Neste sentido, independente de toda ação ser mediada, ela centra-se na interação entre os envolvidos (agentes) e as ferramentas culturais utilizadas na construção do conhecimento. Conforme o contexto e os objetivos que se pretende alcançar, a ação adquire contornos específicos. Segundo Trazzi e Oliveira (2016a; 2016b), na prática educativa a ação mediada tem caráter intencional, envolvendo, neste caso, objetivos explícitos e planejamento educativo. Assim, a ação mediada pode nos ajudar a entender, a partir das especificidades do contexto educativo do museu de ciências, como foi desenvolvida a atividade investigativa. Dessa forma, para compreender o contexto que permeia a ação humana e seu caráter mediado, consideramos a ação mediada (Wertsch, 1999) como unidade de análise.

$\mathrm{Na}$ revisão de literatura, encontramos dois trabalhos que analisaram processos de aprendizagem realizados em diferentes contextos (museus, escola e o ambiente da casa de uma família) tendo a ação mediada como unidade de análise. No primeiro, Raith (2016) investigou como alunos do ensino médio interagem com duas ferramentas culturais em dois contextos diferentes. O estudo investigou como os alunos interagem com artefatos analógicos e digitais no Museu de História Natural da Dinamarca e na sala de aula da educação básica respectivamente.

Neste estudo, primeiro os alunos e o professor foram observados durante uma 
visita ao museu em uma de suas sessões que tratava do tema "a evolução do homem", que foi ministrada por funcionários do museu. A tarefa dada aos alunos foi medir diferentes tamanhos de crânio para estudar a evolução do homem. Uma semana depois, os alunos foram observados na escola, em sua sala de aula, visando identificar como usavam uma versão digital educativa (produzida pelo museu zoológico) da mesma atividade. Novamente, o objetivo era que eles aprendessem sobre a evolução do homem, mas a partir de uma versão digital, o que também significava que as tarefas de medição aconteciam com a régua operada pelo cursor do computador e não com uma régua física. Na visão de Raith (2016), o contexto do museu pareceu favorecer uma mediação sobre evolução humana mais interessante do que a realizada na sala de aula. O contexto do museu teve um efeito positivo tanto no comportamento como no engajamento dos alunos na atividade. Além disso, Raith (2016) observou que o museu proporcionou um contexto em que os alunos compreenderam melhor o conteúdo.

No segundo trabalho, Rowe e Bachman (2012) realizaram uma pesquisa na qual analisaram famílias interagindo em dois contextos: no primeiro contexto, uma família interagia com um aquário habitado por invertebrados marinhos e alguns peixes de estuário do Oceano Pacífico; enquanto no segundo contexto, uma família interagia, em sua casa, com um recurso educativo com o propósito de que um dos membros da família aprendesse sobre Química. Como resultados da análise, as pesquisadoras observaram que a partir da mediação realizada, os membros da família conseguiram fazer conexões com suas experiências e conhecimentos anteriores e tiveram acesso a conhecimentos novos. As autoras observaram que as aprendizagens mediadas por ferramentas culturais serviram tanto para funções comunicativas como cognitivas que passavam pelos objetivos dos participantes na interação e também na maneira como cada membro da família usava as ferramentas culturais disponíveis para a comunicação e o pensamento. Segundo Rowe e Bachman,

"A ação mediada é uma maneira de pesquisar como as pessoas usam todos os tipos de objetos e ferramentas, tanto físicas quanto psicológicas, para estruturar suas interações, comunicar-se e pensar. . . Além disso, porque tenta dar conta dos contextos individuais, sociais, culturais e históricos nos quais a aprendizagem ocorre, uma abordagem de ação mediada pode ajudar a fazer conexões entre estudos interdisciplinares de aprendizagem em contextos de vida" (Rowe, \& Bachman, 2012, p. 143).

E neste sentido, para Rowe e Bachman (2012, p. 143), uma estrutura de ação mediada parte da ideia de "que o aprendizado se origina na interação social; que o aprendizado é mediado pela linguagem e outros sistemas simbólicos e; que o aprendizado está sempre ligado a um contexto social, cultural e histórico".

Assim, compreendemos que a estrutura da ação mediada pode nos ajudar no entendimento sobre como os alunos desenvolvem ações operando com ferramentas culturais ao trabalharem na abordagem do ensino por investigação. Como acontece o processo de aprendizagem na interação social mediada pela linguagem e outros sistemas simbólicos em um determinado contexto? 
Segundo Sá, Lima e Aguiar Junior (2011), apesar de não haver uma única definição para o termo "ensino por investigação", é consenso nesta abordagem de ensino a valorização da ação dos estudantes no processo de aprendizagem, ou seja, agentes (alunos) operando com ferramentas culturais numa tensão irredutível como aponta Wertsch (1999).

Além disso, autores como Sá, Lima e Aguiar Junior (2011) e Azevedo (2009) enfatizam que o contexto em que as atividades investigativas acontecem, durante o processo ensino e aprendizagem, caracteriza muito mais o ensino por investigação do que as atividades em si mesmas. Assim, conforme apontam autores como Azevedo (2009); Borges (2002); Carvalho (2009); Sá, Lima e Aguiar Junior (2011), as atividades investigativas:

1- apresentam um problema que não necessariamente precisa ser um problema aberto $^{1}$. O importante é que este problema precisa ser identificado pelos alunos como susceptível a resolução.

2- valorizam o protagonismo e a autonomia do aluno quando o mesmo se empenha na solução desse problema;

3-implicam uma postura problematizadora do professor em sala de aula, à medida que este não diz de imediato quais seriam as respostas desse problema. O professor provoca o questionamento dos alunos, permitindo que os mesmos levantem hipóteses sobre os possíveis resultados. Desta forma são criadas condições para que os alunos resolvam o problema, contemplando o que Hodson (1998) e Carvalho (2009) chamam de engajar os alunos em fazer ciências. Depois, é preciso que os alunos compreendam o que fizeram, ou seja, o "como conseguiram" e o "porquê", considerando o que Hodson (1998) e Carvalho (2009) chamam de aprender sobre ciências e aprender o conteúdo científico em si;

4- implicam também uma postura ativa dos alunos em sala de aula. Os mesmos precisam se sentir curiosos e instigados a resolver o problema;

5- suscitam debates e argumentação, proporcionando múltiplas interpretações;

Assim, considerando os museus de ciências como espaços educacionais (Marandino, 2010; Nascimento, 2010; Carvalho, 2017) que podem ser utilizados para a realização de atividades investigativas, perguntamos: Como se desenvolve a ação mediada em uma atividade investigativa em um museu de ciências? Quais as ferramentas culturais são empregadas pelos pesquisadores e alunos na condução da atividade?

\section{Metodologia}

Neste trabalho, realizamos um estudo qualitativo, de cunho colaborativo (Franco, 2012). A pesquisa ocorreu em um museu de ciências localizado no Estado do Espírito Santo - Brasil, o Instituto Nacional da Mata Atlântica, que corresponde ao mais antigo local dedicado a pesquisas do Bioma Mata Atlântica no Estado (Roldi et al., 2016).

1 O grau de abertura de um problema segundo Borges (2002), vai depender de o quanto o condutor da atividade ou o roteiro estabelecido especifica ou direciona a atividade para o aluno. 
Desde 2011, o museu possui um programa educativo no qual pesquisadores vinculados ao museu recebem estudantes de escolas com o objetivo de apresentar as coleções zoológicas e explicar alguns conceitos relacionados a cada grupo por meio de um roteiro de atividade. No ano de 2015, uma das autoras deste artigo, na qualidade de professora de ensino médio de uma escola da região, propôs a um dos pesquisadores do museu uma mudança no roteiro trabalhado na edição de répteis do programa educativo com o objetivo de torna-lo investigativo. Com o aceite do pesquisador, foi proposta, pela professora, a realização de uma pesquisa para investigar o desenvolvimento do roteiro junto a um grupo de alunos da $1^{\text {a }}$ série do ensino médio na escola pública estadual em que a professora leciona.

Neste sentido, primeiro a professora proporcionou um momento para esclarecimentos e orientações quanto à participação dos estudantes na pesquisa. Para isso promoveu uma reunião com os alunos que voluntariamente se dispuseram a participar, acompanhados de seus pais, a fim de explicitar todo o processo da pesquisa e explicar sobre o termo de consentimento livre e esclarecido (TCLE). Nesta reunião, as assinaturas dos pais no TCLE foram coletadas, em consonância com as diretrizes da Comissão Nacional de Ética em Pesquisa - CONEP, Resolução n. 196/96. A atividade foi realizada no ano de 2015 e somente 10 estudantes se voluntariaram a participar da pesquisa $^{2}$.

Depois, a professora se reuniu com o pesquisador do museu para discussão da reelaboração do roteiro educativo usado pelo museu com a finalidade de torna-lo investigativo. Até então, as atividades do Projeto eram conduzidas por um pesquisador do museu por meio de um ensino tradicional, que abordava as características dos grupos biológicos estudados por meio de uma exposição de slides, apresentando em seguida os espécimes das coleções didáticas ou do Parque Zoobotânico para ressaltar alguns conceitos ou demonstrar as características enfatizadas durante a exposição. Nesta reunião, os pressupostos do ensino de ciências por investigação foram apresentados e discutidos e, posteriormente, um novo roteiro foi elaborado.

Em um terceiro momento, os alunos puderam visitar todas as sessões do Museu guiados por funcionários do museu. Depois, os estudantes trabalharam juntos, em grupos, em uma sala de educação do museu (laboratório) que era separada do espaço de exposição. A tarefa geral durante a sessão foi trabalhar no roteiro investigativo que foi reelaborado que tratava da temática répteis. $O$ roteiro tem início com uma questão problema na qual os estudantes deveriam solucionar. Para isso eles contavam com a ajuda do pesquisador ${ }^{3}$ do museu e de ferramentas culturais como a coleção de répteis (animais taxidermizados) e um texto adaptado de um livro didático ${ }^{4}$. A sessão durou cerca de duas horas incluindo a visita a exposição.

2 A participação dos alunos na atividade promovida no museu de ciências foi por adesão, sendo realizada no contra turno da escola.

3 Os pesquisadores que ministram as atividades do programa educativo, de modo geral, são bolsistas vinculados ao museu e realizam esse trabalho de acordo com sua área de conhecimento.

4 Mendonça, L. M. (2013). Biologia 2 Ensino Médio. (Cap. 15, 2a ed.). São Paulo: AJS. 
O caráter colaborativo da proposta se configura a partir da parceria verificada nas ações estabelecidas entre a professora da escola e o pesquisador do museu em reuniões formativas com o intuito de reelaborar o roteiro de visitação com a inserção da perspectiva investigativa nas ações educativas já realizadas no museu. Embora o pesquisador fosse experiente em sua área de conhecimento, o contato com os princípios teórico-metodológicos do ensino por investigação foi uma experiência nova e desafiadora, principalmente com relação à mediação pedagógica a ser realizada. Neste sentido, ressaltamos a dimensão formativa do trabalho colaborativo desenvolvido.

No planejamento do roteiro, conforme Figura 01, a atividade investigativa foi planejada, inicialmente, de modo a envolver os alunos no assunto estudado. Para alcançar esse propósito, apresentamos uma situação problema (problematização) com o objetivo de incitar a curiosidade dos estudantes (fase 1). A partir disso, foi solicitado aos estudantes que levantassem hipóteses sobre as possíveis respostas a pergunta problema (fase 2). Em seguida foi pedido aos alunos que testassem suas hipóteses, registrassem suas observações e discutissem os resultados entre si e com o professor a fim de organizarem as informações (fase 3 e fase 4). Na Figura 1 além de apresentarmos o desenvolvimento da ação, também apresentamos as ferramentas culturais (mediadoras na ação) utilizadas durante o ato na interação entre os agentes (estudantes e pesquisador).

\begin{tabular}{|l|l|}
\hline SÉRIE: 1a Série do Ensino Médio $^{\text {DATA 27/07/2016 }}$ \\
\hline TEMA DO ENCONTRO Biologia dos Animais Vertebrados: Répteis & DURAÇÃO 02 horas \\
\hline DESENVOLVIMENTO DA AÇÃO
\end{tabular}

\section{DESENVOLVIMENTO DA AÇÃO}

$1^{\text {a }}$ Fase: é a fase da motivação, nesta fase espera-se que os alunos fiquem curiosos em relação ao assunto estudado. Para alcançar esse propósito apresentamos uma situação problema:

- Vocês foram enviados em uma expedição científica para descobrir porque grande quantidade de animais está morrendo em uma localidade em que as mudanças climáticas tornaram o clima da região muito mais frio que o de costume. Animais como jacarés, lagartos, serpentes e jabutis são encontrados mortos com frequência, sem motivos aparentes para morte, outros animais como anta, onça, gavião, jacu e tatu aparentemente estão normais. Sua função é estabelecer hipóteses para essa mortandade.

$2^{\text {a }}$ Fase: Os grupos foram conduzidos ao laboratório para observar os animais recolhidos (coleção didática do museu) e com auxílio de um texto base adaptado do livro didático Biologia volume 2 Mendonça (2013) tiveram o objetivo de testar suas hipóteses registrando as observações e discutindo os resultados.

$3^{\mathbf{a}}$ Fase: Os grupos realizaram a exposição dos resultados obtidos sobre as características comuns e diferentes entre os animais que morreram e as hipóteses da causa da mortandade. As informações apresentadas foram discutidas entre os participantes da ação.

$4^{a}$ Fase: A partir das informações recolhidas no processo de investigação, os alunos reelaboraram as hipóteses acrescentando os novos conhecimentos (sistematização).

III - FERRAMENTAS CULTURAIS:

Bandejas, Pinças, Luvas, Coleção didática de répteis do museu (animais taxidermizados ou conservados em álcool a 70\%), Papel e Caneta, Linguagem falada, texto adaptado do livro didático.

Figura 1. Roteiro do programa educativo (reelaborado): Répteis 
A produção dos dados foi realizada por meio de gravação de áudio da atividade e por meio de observações com registros em diário de campo feitos pela professora (uma das autoras deste artigo). Posteriormente, todo o áudio foi transcrito e as observações realizadas no diário de campo foram utilizadas para complementar as lacunas presentes na gravação de modo a resgatar o contexto da atividade.

Os dados oriundos das transcrições e registros em diário de campo foram selecionados e apresentados na análise em forma de episódios. Mortimer e Scott (2003), inspirados na noção de enunciação de Bakhtin, definem episódios como segmentos do discurso que têm fronteiras claras, em termos de conteúdo temático, da fase didática ou das tarefas que são desenvolvidas. Assim, para cada ato, ou seja, para aquilo que ocorre na ação ou no pensamento, conforme compreendido por Wertsch (1999), delimitamos um episódio. Em cada episódio, os cinco elementos da ação mediada (ato, cena, agentes, ferramentas culturais e objetivos) são circunscritos e os diálogos são apresentados em um fluxo discursivo contínuo para que não se perca o sentido e o contexto da atividade. Com o objetivo de analisar o desenvolvimento da mediação realizada, procuramos delimitar, para cada episódio, uma categoria de análise baseada nos pressupostos do ensino por investigação conforme as fases apresentadas no roteiro (Figura 1): (i) problematização e levantamento de hipóteses ( $1^{\text {a }}$ fase); (ii) teste de hipóteses ( $2^{\text {a }}$ fase); e (iii) sistematização dos conhecimentos ( $3^{\mathrm{a}}$ e $4^{\mathrm{a}}$ fases).

\section{Resultados e Discussões}

\section{Problematização e levantamento de hipóteses}

O roteiro tem início com o processo de problematização e levantamento de hipóteses, as etapas iniciais de uma sequência de ensino investigativa. Nesta fase ocorreu a apresentação da situação problema, em relação à qual os alunos deveriam levantar hipóteses. Para analisarmos a problematização e o levantamento de hipóteses, o ato se apresenta como o que ocorre na ação ou no pensamento: a explicação da situação problema pelo pesquisador e o processo de levantamento de hipóteses pelos alunos; a cena é o setor de zoologia do museu e configura-se como o contexto em que essas atividades foram realizadas; os agentes, são os sujeitos que realizam a ação ou o pensamento: professores e alunos envolvidos nas etapas de problematização e levantamento de hipóteses acerca da situação problema apresentada no roteiro investigativo que são os propósitos da atividade; e as ferramentas culturais que são utilizadas pelo pesquisador e pelos alunos durante a problematização e o levantamento de hipóteses: papel, caneta, roteiro e a linguagem falada (Figura 2).

Cena: Setor de zoologia do museu.

Agentes: Pesquisador e alunos

Propósito: Realizar a problematização da atividade com a proposição da situação problema e levantamento de hipóteses a partir de conhecimentos dos estudantes.

Figura 2. Descrição do processo de problematização e levantamento de hipóteses (contunua) 


\begin{tabular}{l}
\hline Ato: Leitura e explicação a situação problema e levantamento de hipóteses \\
\hline Ferramentas culturais: Papel, caneta, roteiro investigativo e a linguagem falada. \\
\hline Contexto: O pesquisador se apresenta expondo qual sua linha de pesquisa. Depois da apresentação \\
inicial, expõe o objetivo da atividade e convida os alunos a resolverem o problema. Os alunos se \\
reúnem em grupo para, a partir de seus conhecimentos prévios, levantarem hipóteses para a situação \\
problema proposta no roteiro.
\end{tabular}

Pesquisador: O projeto vai ser sobre répteis no geral, vocês já estudaram répteis na sexta série, já se depararam com muitas informações sobre répteis. Vocês têm um problema para me ajudar a resolver, eu vou deixar uma cópia do roteiro para vocês acompanharem comigo, e aí tem a seguinte situação: Vocês foram enviados a uma expedição científica para descobrir por que grande quantidade de animais está morrendo em uma localidade, em que as mudanças climáticas tornaram o clima da região muito mais frio do que de costume. Esse muito, vocês podem considerar, assim, muito mesmo, mudou drasticamente a temperatura. Animais como jacaré, lagartos, serpentes e jabutis são encontrados mortos com frequência, nesse local, sem motivos aparentes pra morte. Outros animais como anta, onça, gavião, jacu e tatu, aparentemente estão normais. A função de vocês é levantar hipóteses para essa mortandade, e descobrir porque esses animais estão morrendo.

Pesquisador: E aí eu vou fornecer a prancheta pra vocês porque vocês vão fazer anotações das hipóteses, e tem que se dividir em grupos.

Pesquisador: Ok, agora que estão divididos, primeiro vocês vão escolher um para ser o relator, aquele que vai fazer todas as anotações, escolham aí entre vocês.

Pesquisador: Tipo assim gente, olha, tem animal que tá morrendo e tem animal que não tá morrendo, dos que estão morrendo, tem exemplo aí jacaré, lagarto, serpente, jabuti, esses estão morrendo. Pensam que vocês são biólogos que foram contratados pra dizer por que os bichos estão morrendo, e aí vão formular uma hipótese e a partir dela, tentar resolver esse problema. Lembrando que a temperatura caiu muito rapidamente.

Aluno: Mas o jacaré a característica dele não é sangue frio? Tô confuso.

Pesquisador: A temperatura caiu, pensa assim não tá frio igual Santa Teresa, tá muito frio, caindo neve assim. E você falou que o jacaré tem sangue frio, então pensa no conceito de sangue frio.

Aluno: Legal, temos que pensar no por que deles estarem morrendo. Mas, só esses que você listou estão morrendo, os outros não?

Aluno 1: Quais os animais ficaram vivos mesmo?

Pesquisador: Gavião, anta, tatu, jacu, onça

Aluno 2: Agora eu não entendi, por que a anta ficou viva?

Pesquisador: Então, vocês têm que tentar resolver esse problema, por que alguns ficaram vivos?

Aluno 4: Muitos desses animais aqui eu só ouvi falar, eu nunca vi na minha vida.

Pesquisador: Vocês podem nunca ter visto, mas conhecem esses animais, são todos encontrados aqui no Espírito Santo. A maioria deles vocês viram empalhados, lá em cima na exposição. Ok, agora então vamos lá ver o que vocês escreveram.

Aluno 1: Nós achamos que os jacarés suportam temperaturas baixas porque são de sangue frio, mas nem tanto assim e as aves conseguem se proteger do frio com suas penas.

Pesquisador: Beleza. Continuem a conversa entre vocês, terminem o levantamento de hipóteses para depois vocês verificarem se elas vão se confirmar.

Figura 2. Descrição do processo de problematização e levantamento de hipóteses 
O problema proposto na atividade envolvia os mecanismos de regulação da temperatura corpórea, em especial o conceito de ectotermia, sendo, portanto, um problema de natureza teórica.

Para Carvalho (2013), a introdução de uma situação problema possibilita ao aluno uma postura de protagonista na construção do conhecimento, se distanciando do ensino expositivo no qual, normalmente toda a linha de raciocínio centra-se no professor, com o aluno seguindo esse raciocínio e procurando entende-lo, sem ser o agente do pensamento. "Ao fazer uma questão, ao propor um problema, o professor passa a tarefa de raciocínio para o aluno e sua ação não é mais a de expor, mas de orientar e encaminhar as reflexões dos estudantes na construção do novo conhecimento" (Carvalho, 2013, p. 2). No caso desse estudo, o pesquisador ocupou o lugar do professor nesse processo de orientação e encaminhamento das reflexões na construção do novo conhecimento.

$\mathrm{Na}$ apresentação da situação problema, o pesquisador utilizou a linguagem falada e o roteiro investigativo como forma de comunicação com os alunos. Na visão de Capecchi (2013), problematizar é formular problemas diferentes daqueles que os alunos estão acostumados a elaborar, de forma a proporcionar oportunidades para que novos conhecimentos sejam construídos. Na perspectiva de Gil Perez (1986) os alunos devem ser estimulados a levantar hipóteses para a resolução de situações problema ao afirmar que são as hipóteses e todo o conhecimento gerado a partir delas que possibilitam aos alunos atribuir significado aos resultados e pensar o desenho do experimento, propiciando o surgimento de novas ideias cuja relação com a situação problema possa ser testada.

A tensão irredutível entre o agente e as ferramentas culturais, segundo Wertsch (1999) está no centro da aproximação sociocultural. Para explicar a situação problema, o pesquisador necessita de ferramentas culturais (linguagem falada, roteiro), ao mesmo tempo em que as ferramentas culturais não existem separadas ou independentes dos agentes que as operam. Logo, não existe agente sem ferramenta cultural, nem ferramenta cultural sem um agente que possa operá-la. Ainda que seja possível, em determinados momentos, distinguir agente e ferramentas culturais, a relação existente entre eles é tão fecunda que é mais adequado tratar de "agentes-agindo-com-ferramentas-culturais" do que falar de indivíduos simplesmente. Assim pode-se perceber mais adequadamente quem está falando ou quem realiza a ação (Wertsch, 1991).

Embora o pesquisador tenha um objetivo principal, explicar a situação problema aos alunos, Wertsch (1999) diz que a ação mediada, em geral, tem múltiplos objetivos simultâneos. Assim, mesmo o pesquisador tendo um objetivo principal, considera outros objetivos para que a condução da tarefa proposta seja efetuada. O pesquisador necessita dividir os grupos, direcionar os alunos e chamar a atenção para a necessidade de eles manterem o foco no levantamento de hipóteses, não se desviando do objetivo principal. A descrição abaixo ilustra os múltiplos objetivos da ação mediada durante a atividade investigativa. 
Pesquisador: E aí eu vou fornecer a prancheta pra vocês porque vocês vão fazer anotações das hipóteses, e tem que se dividir em grupos.

Pesquisador: Ok, agora que estão divididos, primeiro vocês vão escolher um para ser o relator, aquele que vai fazer todas as anotações, escolham aí entre vocês.

No primeiro momento, o pesquisador direcionou os alunos para os materiais que seriam entregues e, em seguida passou para a divisão dos grupos de trabalho, momento em que o objetivo principal deixou de ser a explicação da situação problema e passou a ser o direcionamento das atividades a serem desenvolvidas, objetivando a organização da etapa de levantamento de hipóteses. Ainda em relação aos múltiplos objetivos, o pesquisador solicitou que os alunos elegessem um relator para a transcrição das hipóteses levantadas pelo grupo.

Quanto aos múltiplos objetivos dos alunos, podemos utilizar a mesma situação descrita para demonstrar que, apesar de o objetivo principal ser o levantamento de hipóteses, outros objetivos surgiram no decorrer da ação. Os alunos se concentraram na divisão dos grupos e elegeram um relator para representa-los, necessitando, para essa tarefa, negociação e persuasão para a escolha do relator. Realizadas essas ações, os alunos se concentraram no levantamento de hipóteses.

A situação problema apresentada para os alunos durante a atividade investigativa se caracterizou pelo interesse e motivação na busca do levantamento de hipóteses. Os alunos se sentiram desafiados com a situação apresentada e isso fez com que o empenho no levantamento de hipóteses se manifestasse. A transcrição abaixo reflete o empenho do aluno do grupo 1 durante o levantamento de hipóteses,

Pesquisador: Tipo assim gente, olha, tem animal que tá morrendo e tem animal que não tá morrendo, dos que estão morrendo, tem exemplo aí jacaré, lagarto, serpente, jabuti, esses estão morrendo. Pensem que vocês são biólogos que foram contratados pra dizer por que os bichos estão morrendo, e aí vão formular uma hipótese e a partir dela, tentar resolver esse problema. Lembrando que a temperatura caiu muito rapidamente.

Aluno: Mas o jacaré a característica dele não é sangue frio? Tô confuso.

Pesquisador: A temperatura caiu, pensa assim não tá frio igual Santa Teresa, tá muito frio, caindo neve assim. E você falou que o jacaré tem sangue frio, então pensa no conceito de sangue frio.

Aluno: Legal, temos que pensar no por que deles estarem morrendo. Mas, só esses que você listou estão morrendo, os outros não?

A transcrição da conversa demonstrou o interesse do aluno em estabelecer uma hipótese para o problema apresentado, pois ele questionou e refletiu sobre o que estava acontecendo. A transcrição também evidencia a postura do pesquisador junto ao aluno, visando contribuir para que ele próprio (aluno) construísse sua hipótese a partir de seus conhecimentos prévios. Todas essas interações reforçam a ideia de que o ensino de 
ciências deve despertar a curiosidade e o interesse do aluno.

$\mathrm{Na}$ fase de problematização e levantamento de hipóteses, a interação ocorreu principalmente por meio da ferramenta cultural linguagem falada. $O$ pesquisador apresentou uma situação problema, enquanto os alunos se esforçavam para levantar hipóteses (Figura 2). A transcrição a seguir traz a interação discursiva entre os integrantes do grupo 1 enquanto realizavam o levantamento de hipóteses.

Aluno 1: Quais os animais ficaram vivos mesmo?

Pesquisador: Gavião, anta, tatu, jacu, onça

Aluno 2: Agora eu não entendi, por que a anta ficou viva?

Pesquisador: Então, vocês têm que tentar resolver esse problema, por que alguns ficaram vivos?

Aluno 4: Muitos desses animais aqui eu só ouvi falar, eu nunca vi na minha vida.

Pesquisador: Vocês podem nunca ter visto, mas conhecem esses animais, são todos encontrados aqui no Espírito Santo. A maioria deles vocês viram empalhados, lá em cima na exposição. Ok, agora então vamos lá ver o que vocês escreveram.

Aluno 1: Nós achamos que os jacarés suportam temperaturas baixas porque são de sangue frio, mas nem tanto assim e as aves conseguem se proteger do frio com suas penas.

Pesquisador: Beleza. Continuem a conversa entre vocês, terminem o levantamento de hipóteses para depois vocês verificarem se elas vão se confirmar.

$\mathrm{Na}$ busca de verificar o que os alunos já sabiam sobre o tema, o pesquisador interagiu com os componentes do grupo sem fornecer as respostas prontas, dando autonomia na construção das hipóteses. $\mathrm{O}$ aluno 1 disse que o jacaré, por ter sangue frio, suportaria temperaturas baixas. No entanto, mesmo percebendo o equívoco, o pesquisador não forneceu a resposta, indicando que continuassem a levantar hipóteses.

Depois de conversarem entre si, os estudantes elaboraram duas hipóteses para responder a situação problema:

Hipótese do Grupo 1: O jacaré suporta certas temperaturas, mas nem tanto, lagarto não sabemos direito, acho que é a mesma coisa. O gavião com sua plumagem se protege do frio, a onça com a pele se protege, o jacu também tem plumagem e o tatu cava buraco para se esquentar, para se proteger.

Hipótese do Grupo 2: Nós achamos que os animais que estão morrendo têm sangue frio e como ficou muito frio e provavelmente eles não tinham como se aquecer, acabaram morrendo e os outros animais conseguem produzir seu próprio calor.

A hipótese elaborada pelo grupo 1 revela uma incompreensão dos mecanismos de regulação de temperatura nos animais em questão. Por outro lado, a hipótese elaborada 
pelo grupo 2 vai ao encontro de uma compreensão do mecanismo de regulação de temperatura dos animais quando dizem “(...) os outros animais conseguem produzir seu próprio calor".

A elaboração de hipóteses é um processo importante, porque aproxima a construção do conhecimento escolar ao trabalho científico ao possibilitar que os alunos articulem seus conhecimentos prévios e busquem outros para formular possíveis respostas ou soluções a questões problema (Gil-Perez, \& Carvalho, 2000). Assim, findadas as etapas da problematização e do levantamento de hipóteses, o teste das hipóteses passa a ser o foco principal da atividade investigativa.

\section{Teste de hipóteses}

Diante da situação problema apresentada pelo pesquisador, os alunos levantaram hipóteses para a resolução do problema. Para o teste das hipóteses da atividade investigativa, novamente caracterizamos os cinco elementos da ação mediada. $\mathrm{O}$ ato é aquilo que ocorre na ação ou no pensamento: a utilização da coleção didática de répteis do museu e o texto adaptado do livro didático durante o teste das hipóteses e a reflexão dos alunos testando as hipóteses e fazendo questionamentos ao pesquisador; a cena refere-se ao contexto no qual ocorreu o ato: setor de zoologia do museu; o agente é quem realizou a ação ou pensamento: o pesquisador que conduziu a ação e os alunos que testam as hipóteses e formulam explicações; o propósito configura-se na intenção de: proporcionar condições para que os alunos testem suas hipóteses acerca dos conceitos biológicos apresentados na atividade investigativa e formulem explicações acerca dos conteúdos biológicos; e as ferramentas culturais que são instrumentos utilizados: linguagem falada, coleção didática de répteis e texto adaptado do livro didático (Figura 3).

\begin{tabular}{|l|}
\hline Cena: setor de zoologia do museu. \\
\hline Agentes: Pesquisador e alunos. \\
\hline Ato: Teste de hipóteses e elaboração de explicações. \\
\hline Propósito: Teste das hipóteses; formulação de explicações. \\
\hline $\begin{array}{l}\text { Ferramentas culturais: Linguagem falada, coleção didática de répteis e texto adaptado do livro } \\
\text { didático. }\end{array}$ \\
\hline $\begin{array}{l}\text { Contexto: o pesquisador solicita que os grupos formados para o levantamento de hipóteses } \\
\text { permaneçam juntos e utilizem a coleção didática de répteis e o material escrito oferecido para testar } \\
\text { suas hipóteses. }\end{array}$ \\
\hline
\end{tabular}

Figura 3. Descrição do processo do teste de hipóteses (continua) 
Aluno 1: Olha aqui essa tartaruga, igual minhas tartarugas lá de casa.

Aluno 2: Sapo é anfíbio ou réptil? Não tô vendo sapo aqui.

Aluno 3: Ah, é verdade, sapo é anfíbio por isso não está aqui.

Aluno 4: E as lagartixas? Tem um lagarto lá em casa.

Aluno 1: Olha ali um vidro cheio de lagartixa.

Aluno 3: Tipo, lá na roça a gente encontra cobra... tipo, na nascente aonde fica muita folhagem.

Aluno 2: Aqui no texto tá falando da adaptação e da ectotermia.

Aluno 3: É essa parte aqui que fala que ele se adapta ao ambiente, tipo a tartaruga, igual você falou, conforme o ambiente, ela consome menos energia do corpo.

Aluno 1: É porque, igual se ela tá na água fria ela fica quietinha.

Aluno 1: Eu tenho duas tartarugas no aquário que é quente por causa do aquecedor e uma que fica lá fora por causa do poço, e a que fica lá fora no poço fica tão quietinha e até tinha duas e uma morreu de hipotermia, porque elas não podem ficar na água fria.

Aluno 2: Tem certeza que tartaruga é réptil?

Aluno 3: Claro né, se não elas não estariam aqui pra gente testar as hipóteses.

Aluno 1: Na água fria, tipo elas hibernam.

Aluno 3: É urso agora?

Aluno 1: Tá, elas ficam mais quietas para economizar energia. Sei lá, vamos perguntar pro pesquisador.

Pesquisador: Tá, vamos lá então. O Nosso metabolismo produz calor e aí aquece. No caso deles isso não acontece. Então, eles são pecilotérmicos, são animais que se aquecem com o calor do ambiente. Então é muito comum você vê a tarde, principalmente quando tá em campo, uma pedra, por exemplo, ficou um dia inteiro tomando sol, aí no final da tarde os bichinhos vão pra lá. Por isso que a gente vê muito calango no muro, porque no muro bate sol. Aqui atrás tem bastante sol, no jardim rupestre, então eles se aquecem ali. Não são todas as espécies de répteis que vão diretamente pro sol, mas eles se aquecem com o ambiente. Quando a gente cria em cativeiro igual lá no ofidiário, lá tem um quadradinho de barro e tem um aquecedor que liga na tomada e esquenta o barro, e aí a serpente fica ali em cima se aquecendo. Supre o calor do ambiente que ela precisa. E aí o que a gente pode observar aqui ...é.... características diferentes é... os jacarés tem o corpo todo coberto por um couro, as serpentes e os lagartos tem escamas e os quelônios, os jabutis tem placas dérmicas, essa que a gente tá observando aqui e por baixo dela o esqueleto. E aqui nós temos dois animais, uma tartaruga e o outro é um cágado, e gente pode observar aqui. Então eles estão todos três agrupados no grupo de quelônios, mas eles têm diferenças tanto no corpo como nos hábitos.

Aluno 2: Acho que é isso então: As características dos que morreram foi porque todos são répteis e os animais que morreram dependem do calor do ambiente para se aquecerem. Então assim, nossa hipótese não se confirmou, porque um ectotérmico não é aquele que suporta baixas temperaturas. Pelo contrário, eles precisam do calor do ambiente para aumentar seu metabolismo. Aqueles que não morreram conseguem produzir calor do seu corpo.

Figura 3. Descrição do processo do teste de hipóteses

Nesta fase de teste de hipóteses, as ferramentas culturais utilizadas são um texto adaptado do livro didático, a coleção didática de répteis do museu e a linguagem falada. Estas ferramentas culturais são consideradas específicas, pois podem atuar como 
possiblidades para o entendimento do conceito de ectotermia e endodermia, ou seja, ferramentas concretas para uma questão considerada abstrata. Isso ocorre na medida em que esses animais e o texto oferecem uma materialidade ao conceito. Assim, os alunos conseguem materializar tais características, tornando-as menos abstratas para a significação dos conceitos.

A transcrição a seguir ilustra o pesquisador instruindo os alunos para o teste de hipóteses, a fim de verificarem as hipóteses estabelecidas registrando as observações e discutindo os resultados, "Agora vocês vão tentar confirmar suas hipóteses. De que forma? Com um texto que vocês vão poder acompanhar, ler sobre os repteis e olhando os animais (coleção de répteis) ".

A partir do diálogo visto na Figura 3, os alunos, mesmo com o texto adaptado e vários exemplares de répteis para examinar, sentiram a necessidade de pedir auxílio ao pesquisador durante o teste de hipóteses. Como já apresentado na Figura 3, os alunos interagem com os animais e com texto adaptado utilizando-os como ferramenta cultural, mas também buscam a explicação do pesquisador conforme diálogo a seguir:

Aluno 2: Aqui no texto tá falando da adaptação e da ectotermia

Aluno 3: É essa parte aqui que fala que ele se adapta ao ambiente, tipo a tartaruga, igual você falou, conforme o ambiente, ela consome menos energia do corpo.

Aluno 1: É porque, igual se ela tá na água fria ela fica quietinha.

Aluno 1: Tá, elas ficam mais quietas para economizar energia. Sei lá, vamos perguntar pro pesquisador.

A interação entre os alunos apresentada no diálogo acima, se apresentou muito rica demonstrando que o teste de hipóteses foi construído a partir de argumentações pautadas nas ferramentas culturais (coleção didática de répteis e texto adaptado) oferecidas para a resolução do problema apresentado, bem como nas argumentações dos envolvidos.

Os alunos solicitaram o auxílio do pesquisador no decorrer da atividade investigativa provavelmente porque o percebiam como um membro mais experiente, cabendo-lhe a orientação dos trabalhos. O pesquisador, em contrapartida, esclareceu as dúvidas durante o teste de hipóteses, apresentando conceitos que serviram de base para o entendimento dos conteúdos estudados na atividade investigativa conforme trecho

Pesquisador: Tá, vamos lá então. O Nosso metabolismo produz calor e aí aquece. No caso deles isso não acontece. Então, eles são pecilotérmicos, são animais que se aquecem com o calor do ambiente. Então é muito comum você vê a tarde, principalmente quando tá em campo, uma pedra, por exemplo, ficou um dia inteiro tomando sol, aí no final da tarde os bichinhos vão pra lá. Por isso que a gente vê muito calango no muro, porque no muro bate sol. Aqui atrás tem bastante sol, no jardim rupestre, então eles se aquecem ali. Não são todas as espécies de répteis que vão diretamente pro sol, mas eles se aquecem com o ambiente. Quando a gente cria em cativeiro igual lá no ofidiário, lá tem um 
quadradinho de barro e tem um aquecedor que liga na tomada e esquenta o barro, e aí a serpente fica ali em cima se aquecendo. Supre o calor do ambiente que ela precisa.

Se por um lado a introdução da coleção didática de répteis como nova ferramenta cultural (em contraste com o livro didático que os alunos já são acostumados a utilizar na escola) transformou a ação mediada (Wertsch, 1999), somente após a explicação do pesquisador sobre os fenômenos que os alunos compreenderam que um animal ectodérmico não é aquele que suporta baixas temperaturas. Embora no ensino por investigação o professor não deva fornecer as respostas para o problema antecipadamente, ele deve fornecer elementos para que os alunos continuem seu raciocínio e possam chegar a conclusões,

Aluno 2: Acho que é isso então: As características dos que morreram foi porque todos são répteis e os animais que morreram dependem do calor do ambiente para se aquecerem. Então assim, nossa hipótese não se confirmou, porque um ectotérmico não é aquele que suporta baixas temperaturas. Pelo contrário, eles precisam do calor do ambiente para aumentar seu metabolismo. Aqueles que não morreram conseguem produzir calor do seu corpo.

O aluno, então, refutou sua hipótese inicial compreendendo o mecanismo de regulação da temperatura destes animais. De acordo com Schmidt-Nielsen (1996); Pough, Heiser, e Mcfarland (2008) os termos sangue frio e sangue quente e seus correspondentes, ectotermia e endotermia, estão bem consolidados na literatura. No entanto, para os autores, são imprecisos e podem levar ao engano, porque animais conhecidos como de sangue frio como os répteis e os anfíbios não são necessariamente animais frios. Dependendo do ambiente, suas temperaturas corporais podem ficar elevadas até mais do que a de um mamífero, considerado animal de sangue quente. A expressão sangue frio, por vezes, pode induzir os alunos a pensar em baixas temperaturas associadas a esses animais.

A ferramenta cultural linguagem falada, na forma de explicação do professor, e o texto adaptado foram importantes para o entendimento de que a hipótese levantada estava sendo refutada, como aponta o aluno 2 neste trecho “então, assim..., nossa hipótese não se confirmou, porque um ectotérmico não é aquele que suporta baixas temperaturas $[\ldots]$..

Wertsch (1999) aponta para a indissociabilidade entre a ferramenta cultural e o agente. Se houver a separação da ferramenta cultural do agente, a ação mediada não ocorre. Wertsch (1999) destaca que não devemos considerar as ferramentas culturais como determinantes da ação de um modo estático e mecânico. Ferramentas culturais, como a linguagem falada, são incapazes de fazer quaisquer coisas por si mesmas. Somente podem quando usadas por um agente que saiba operar com elas.

Finalizamos o teste das hipóteses inspirando-nos na perspectiva de que a ação modifica e transforma àqueles que participam dela. Ainda nessa perspectiva analisamos a terceira etapa da atividade investigativa, a sistematização dos conhecimentos. 


\section{Sistematização dos conhecimentos}

Para a análise da sistematização dos conhecimentos, centramo-nos na interação entre os agentes (pesquisador e alunos) e as ferramentas culturais utilizadas no contexto estudado e com o propósito de realizar a organização do conhecimento. Enfatizamos como os agentes utilizaram as ferramentas culturais (domínio) e como escolheram as ferramentas culturais e as inseriram em suas ações (apropriação).

\begin{tabular}{|l|}
\hline Cena: Setor de zoologia do museu. \\
\hline Agentes: Pesquisador e alunos \\
\hline Propósito: Sistematizar o conhecimento \\
\hline Ato: Interação entre alunos e pesquisador para compreender como e porque solucionaram o problema \\
\hline $\begin{array}{l}\text { Ferramentas culturais: Papel, caneta, roteiro investigativo, coleção de répteis, texto adaptado e a } \\
\text { linguagem falada. }\end{array}$
\end{tabular}

Contexto: O pesquisador dialoga com os alunos, buscando leva-los a compreender o como e o porquê conseguiram resolver o problema.

Aluno 4: Todos os animais que morreram são répteis e dependem do calor do ambiente. para se aquecerem. É porque eles são de sangue frio, por isso não suportam temperaturas baixas, pelo contrário eles precisam de calor do ambiente para produzir seu próprio calor.

Pesquisador: Ok, mas como seu grupo chegou a essa conclusão?

Aluno 4: Quando nós fomos lendo aquele texto que você deu pra gente, e fomos comparando com os bichos da coleção.

Aluno 1. Mas, assim, ficou difícil, só olhando, porque a gente via o casco da tartaruga e via também que todos eles tinham pele bem grossa e isso podia ajudar, mas só olhando não dava para perceber, entende? Aí precisamos ver o que era sangue frio no texto e depois pedimos sua ajuda, e quando você explicou ficou bem mais claro. Então a gente conseguiu chegar à conclusão.

Pesquisador: E os outros animais, por que eles não morreram?

Aluno 4: Os outros que não morreram (pelo menos não naquele momento) porque se a temperatura continuasse a cair tanto assim, eles também morreriam, eles conseguem produzir calor com seu próprio metabolismo.

Pesquisador: Então eles não morreram porque são endotérmicos?

Aluno 4: Isso, são endotérmicos.

Pesquisador: Mas então, por que também morreriam se a temperatura continuasse a cair?

Aluno 4: Porque mesmo aqueles que produzem seu próprio calor também tem adaptações para viver em certos locais.

Pesquisador: Alguém pode dar um exemplo.

Aluno 5: O urso polar, a professora falou que ele é peludo e tem muita gordura que protege ele do frio. O urso ia sobreviver nessa temperatura, mas o tatu e anta não têm isso. Por isso eu acho que eles podiam morrer com o tempo.

Figura 4. Descrição do processo de sistematização do conhecimento

Para analisarmos a etapa de sistematização do conhecimento, focamos no ato para compreendermos como os alunos dominaram e se apropriaram das ferramentas 
culturais utilizadas na ação. Segundo Wertsch (1999), na ação mediada, a relação dos agentes com as ferramentas culturais pode caracterizar-se do ponto de vista do domínio e da apropriação. O "domínio" pode ser caracterizado considerando como os sujeitos usam ou operam com determinadas ferramentas culturais (físicas ou mentais) na interação. A "apropriação" diz respeito ao processo em que os agentes tomam algo do outro e o tornam próprio. Para Nascimento (2010), a apropriação está relacionada a como os sujeitos escolhem as ferramentas culturais e as inserem em suas ações.

Neste sentido, a sistematização do conhecimento se articula ao modo como os agentes dominaram as ferramentas culturais e se apropriaram dos conhecimentos para construir significados e organizar o pensamento. Este processo passou pelas explicações e argumentações que os alunos construíram a partir do domínio das ferramentas culturais utilizadas, evidenciando uma apropriação de termos e conceitos necessários à compreensão da resolução da situação problema. Isto pode ser evidenciado a partir do diálogo:

Aluno 4: Todos os animais que morreram são répteis e dependem do calor do ambiente para se aquecerem. É porque eles são de sangue frio, por isso não suportam temperaturas baixas, pelo contrário eles precisam de calor do ambiente para produzir seu próprio calor.

Pesquisador: Ok, mas como seu grupo chegou a essa conclusão?

Aluno 4: quando nós fomos lendo aquele texto que você deu pra gente, e fomos comparando com os bichos da coleção.

Aluno 1: Mas, assim, ficou difícil, só olhando, porque a gente via o casco da tartaruga e via também que todos eles tinham pele bem grossa e isso podia ajudar, mas só olhando não dava para perceber, entende? Aí precisamos ver o que era sangue frio no texto e depois pedimos sua ajuda, e quando você explicou ficou bem mais claro. Então a gente conseguiu chegar à conclusão.

Neste trecho da interação, o aluno 4 explicou porque os animais (répteis) morreram, demostrando apropriação de termos como "calor", "temperatura", animais de "sangue frio" e fornecendo uma explicação científica para o ocorrido “(...) eles são de sangue frio, por isso não suportam temperaturas baixas, pelo contrário, eles precisam de calor do ambiente para produzir seu próprio calor". Para chegar a esta conclusão, o aluno 4 argumentou que precisou utilizar as ferramentas culturais "texto adaptado e a coleção de répteis". No entanto, o aluno 1 argumentou que somente olhando a coleção de répteis seria difícil chegar a uma conclusão. Ele também apontou que o domínio das ferramentas culturais "texto adaptado e a ajuda do pesquisador" foram fundamentais no processo de apropriação do conhecimento.

As interações discursivas estabelecidas entre os alunos e o pesquisador constituíram-se em uma característica importante em toda a atividade investigativa, porque proporcionaram um espaço crítico e de argumentação similar ao contexto do 
ambiente científico. Por meio do diálogo os alunos aprenderam a argumentar e defender suas ideias conforme evidenciado no trecho a seguir:

Pesquisador: E os outros animais, por que eles não morreram?

Aluno 4: Os outros que não morreram (pelo menos não naquele momento) porque se a temperatura continuasse a cair tanto assim eles também morreriam, eles conseguem produzir calor com seu próprio metabolismo.

Pesquisador: Então eles não morreram porque são endotérmicos?

Aluno 4: Isso, são endotérmicos.

Pesquisador: Mas então, por que também morreriam se a temperatura continuasse a cair?

Aluno 4: Porque mesmo aqueles que produzem seu próprio calor também tem adaptações para viver em certos locais.

Pesquisador: Alguém pode dar um exemplo.

Aluno 5: O urso polar, a professora falou que ele é peludo e tem muita gordura que protege ele do frio. O urso ia sobreviver nessa temperatura, mas o tatu e anta não tem isso, por isso eu acho que eles podiam morrer com o tempo.

A partir da interação estabelecida, o pesquisador retomou a problematização e perguntou por que os outros animais não morreram. Ao fazer tal pergunta, o pesquisador tinha como objetivo mostrar a todos os alunos que os animais que sobreviveram são endotérmicos. Para isso, ele desenvolveu uma interação com os alunos, solicitando que o aluno 4 contasse como eles haviam concluído que os répteis são ectotérmicos. Em seguida, ele continuou o questionamento a fim de que os alunos pudessem expor por que os endotérmicos poderiam morrer se a temperatura continuasse caindo. $\mathrm{Na}$ resposta, o aluno 4 trouxe características adaptativas dos seres vivos para sobreviverem em um determinado habitat e o aluno 5 concluiu com o exemplo de adaptações do urso polar para viver em uma região inóspita.

Como o pesquisador utilizou perguntas para manter a interação, os alunos puderam argumentar sobre o tema com organização e coerência, aproximando-se de atitudes científicas com o pesquisador questionando-os e estimulando-os a refletirem sobre todo transcurso da atividade investigativa. Esse contexto e o modo como o pesquisador conduziu a conversa, estimulou o desejo de vários alunos participarem da conversação.

Carvalho (2013) entende que, ao ouvir o aluno, o professor faz com que ele não só relembre o que fez, mas também o auxilia na construção dos conhecimentos. Por meio do diálogo e de perguntas, o professor pode levar o aluno a tomar consciência da sua ação (Carvalho, 2013). Nesse caso, o pesquisador é aquele que assume esse papel de mediar as discussões e organizar o conhecimento junto aos alunos. Este momento 
da atividade investigativa é muito importante, pois esse é o momento da organização coletiva do conhecimento.

Quando o pesquisador se utilizou de perguntas, teve o propósito de despertar o interesse para a ação que estava ocorrendo naquele momento. Segundo Wertsch (1999), na ação intencional de perguntar, o propósito da ação é muito importante, evidenciando o pretendido.

Para conduzir a atividade, o pesquisador criou as condições em um determinado contexto e disponibilizou ferramentas culturais nesse contexto para que os alunos entendessem o processo de ectotermia, endodermia e adaptação. Ou seja, que alguns animais não conseguem produzir calor por meio de seu metabolismo, e, por isso, necessitam de fonte externa de calor, bem como possuem características morfológicas para sobreviverem em determinados ambientes. Com isso, o pesquisador trabalhou o tema de forma participativa dando autonomia e garantindo a participação ativa dos alunos na construção do conhecimento, aproximando-os do contexto científico.

\section{Conclusões e implicações}

Esta pesquisa teve como objetivo analisar a mediação de uma atividade investigativa realizada com alunos do ensino médio de uma escola pública estadual do Espírito Santo, em um projeto educativo desenvolvido em um museu de ciências, tendo sido guiada pelas seguintes questões de investigação: Como se desenvolve a ação mediada em uma atividade investigativa, na perspectiva do ensino de ciências por investigação, em um museu de ciências? Quais são as ferramentas culturais empregadas pelos pesquisadores e alunos (agentes) na condução da atividade?

A ação mediada se desenvolveu, inicialmente, por meio do processo colaborativo entre a professora da escola e o pesquisador do museu, com o objetivo de reelaborar o roteiro utilizado no museu durante seu programa educativo. Neste processo de reelaboração do roteiro, os princípios teóricos e metodológicos do ensino por investigação foram discutidos e incorporados ao roteiro. Entre as ferramentas culturais utilizadas para o desenvolvimento do roteiro investigativo, foram usadas a coleção de répteis do museu (animais taxidermizados), um texto adaptado de um livro didático que explicava conceitos como ectodermia e endotermia e a linguagem falada ocorrida durante a interação do pesquisador com os alunos (agentes). Para o desenvolvimento do roteiro, um problema foi apresentado aos alunos; os mesmos foram instigados a levantar hipóteses sobre os motivos do problema estar acontecendo; foram solicitados a testar suas hipóteses tendo como base as ferramentas culturais disponíveis; e, por último, sistematizaram o conhecimento por meio de explicações e argumentações através dos quais puderam demonstrar domínio e apropriação de conceitos como endodermia e ectodermia, fundamentais para a resolução do problema inicial.

Identificamos como contribuição deste estudo que a forma como a ação mediada se desenvolveu colaborou para que os estudantes pudessem operar com as diversas ferramentas culturais disponíveis de modo ativo na construção do conhecimento 
científico. Isso foi possível porque houve um trabalho colaborativo entre a professora da escola e o pesquisador do museu que implicou na mudança do roteiro até então utilizado no programa educativo e, consequentemente, na mediação a ser realizada junto aos alunos. Com a incorporação da perspectiva do ensino por investigação no roteiro, o foco da ação passou a ser na interação entre os agentes que operam com ferramentas culturais, implicando, assim, em uma participação ativa dos estudantes na resolução da questão problema.

Como implicações, apontamos a necessidade de realização de estudos de longo prazo que analisem os desdobramentos dessas ações educativas na interface museu e escola. Tais estudos podem investigar questões como, por exemplo: como atividades desta natureza, realizadas em um museu de ciências, podem afetar as relações de ensino e aprendizagem no contexto escolar e no contexto do museu? Quais os desdobramentos e impactos nas ações da escola e do museu? Como estas atividades são apropriadas (ou não) na escola e no museu? Como são disponibilizadas (ou não)? Como afetam (ou não) os modos de ensinar ciências na escola e no museu? Quais os resultados/efeitos na aprendizagem dos alunos? Estas e outras questões poderão ajudar a compreender outras possibilidades de se trabalhar/pesquisar atividades investigativas em espaços de educação não formal em articulação com a escola tendo como base a ação mediada como unidade de análise.

\section{Referências}

Azevedo, M. C. P. S. (2009). Ensino por Investigação: problematizando as atividades em sala de Aula. In A. M. P. Carvalho (Org.), Ensino de Ciências: unindo a pesquisa e a prática. (pp. 19-33). São Paulo, SP: Cengage Learning.

Bakhtin, M. (2009). Marxismo e filosofia da linguagem. (13a ed.). São Paulo: HUCITEC.

Borges, A. T. (2002). Novos rumos para o laboratório escolar de ciências. Caderno Brasileiro de Ensino de Física, 19(3), 291-313. Recuperado de https://periodicos.ufsc.br/ index.php/fisica/article/view/6607/6099

Capecchi, M. C. V. M. (2013). Problematização no ensino de ciências. In A. M. P. Carvalho (Org.), Ensino de ciências por investigação: Condiçães para implementação em sala de aula. (pp. 21-39).São Paulo, SP: Cengage Learning.

Carvalho, A. M. P. (2017). Os estágios nos cursos de licenciatura. São Paulo: Cengage Learning.

Carvalho, A. M. P. (2013). O ensino de ciências e a proposição de sequências de ensino investigativas. In A. M. P. Carvalho (org.). Ensino de ciências por investigação: Condições para implementação em sala de aula. (pp. 129-145). São Paulo, SP: Cengage Learning.

Carvalho, A. M. P. (2009). Critérios estruturantes para o ensino das ciências. In A. M. P. Carvalho (org.), Ensino de ciências: unindo a pesquisa e a prática. (pp. 01-17). São Paulo, SP: Cengage Learning. 
Franco, M. A. R. S. (2012). Pedagogia e prática docente. São Paulo: Cortez.

Gil-Perez, D. (1996). La metodologia científica y la enseñanza de las ciências: unas relaciones controvertidas. Enseñanza de las Ciencias: Revista de investigación y experiencias didácticas., 4(2), 111-121. Recuperado de https://www.raco.cat/index.php/ Ensenanza/article/view/50876

Gil-Pérez, D., \& Carvalho, A. M. P. (2000). Formação de professores de Ciências: tendências e inovações. (4a ed.). São Paulo: Cortez.

Hodson, D. (1998). Exploring and developing personal understanding through pratical work. In D. Hodson. Teaching and learning science: Towards personalized approach. (pp.143-154). Buckingham: Open University Press.

Mortimer, E. F., \& Scott, P. (2003). Meaning making in secondary science classrooms. Maidenhead, Philadelphia: Open University Press.

Munford. D., \& Lima, C. M. E. C. (2007). Ensinar Ciências por investigação: Em que estamos de acordo? Revista Ensaio: Pesquisa em Educação em Ciências. 9(1), 89-111. https://dx.doi.org/10.1590/1983-21172007090107

Marandino, M. (2010). Museus e educação: discutindo aspectos que configuram a didática museal. In A. Dalben, J. Diniz, L. Leal, \& L. Santos (Orgs). Coleção didática e prática de ensino: Convergências e tensões no campo da formação e do trabalho docente. (pp.89-400). Belo Horizonte: Autêntica.

Nascimento, S. S. (2010). A relação museu e escola na prática docente: Tensões de uma atividade educativa. In A. Dalben, J. Diniz, L. Leal, \& L. Santos (Orgs). Coleção didática e prática de ensino: Convergências e tensões no campo da formação e do trabalho docente. (pp. 370-388). Belo Horizonte: Autêntica.

Pough, F. H., Heiser, J. B., \& Mcfarland, W. N. (2008). A vida dos vertebrados. (4a ed.) São Paulo: Atheneu.

Raith, S. (2016). The Meaning of Context: Upper Secondary Students' Meaning-Making and Engagement with Analogue and Digital Artefacts in the Museum and at School. In O. Erstad, K. Kumpulainen, A. Mäkitalo, K. C. Shroder, P. Pruulmann-Vengerfeldt, \& T. Jóhannsdóttir (Eds.). Learning across contexts in the knowledge society. (pp. 111-130). Rotterdam, Boston \& Taipei: Sense.

Roldi, M. M. C, Soares, L. M. S., Pinheiro, R. F. M., Soares, R. B., Serpa, A. Pugnal, F. L., \& Silva, M. A. J. (2016). Projeto jovens pesquisadores: ensino de biologia e divulgação científica em um espaço não formal de educação em Santa Teresa no Espírito Santo. Revista da SbenBio. 9. VI Enebio e VIII Erebio Regional 3, 574-684. Recuperado de http://www.sbenbio.org.br/wordpress/wp-content/uploads/renbio-9/pdfs/1659.pdf 
Rowe, S., \& Bachman, J. (2012). Mediated action as a framework for exploring learning in informal settings. In D. Ash, J. Rahm, \& L. Melber (Eds.), Putting theory into practice:tools for research in informal settings. (pp. 143-163). Rotterdam, Boston \& Taipei: Sense.

Sá, E. F., Lima, M. E. C. C., \& Aguiar Júnior, O. (2011). A construção de sentidos para o termo ensino por investigação no contexto de um curso de formação. Investigações em Ensino de Ciências. 16(1), 79-102. Recuperado de https://www.if.ufrgs.br/cref/ojs/ index.php/ienci/article/view/247/173

Schmidt-Nielsen, K. (1996). Fisiologia Animal: Adaptação e Meio Ambiente. São Paulo, Santos: Livraria Editora.

Trazzi, P. S. S., \& Oliveira, I. M. (2016 b) O processo de apropriação dos conceitos de fotossíntese e respiração celular por alunos em aulas de Biologia Revista Ensaio: Pesquisa em Educação em Ciências. 18(1), 85-106. Recuperado http://www.scielo.br/ scielo.php?pid=S198321172016000100085\&script=sci_abstract\&tlng=pt 10.1590/198321172016180105

Trazzi, P. S. S., \& Oliveira, I. M. (2016 a) Ação mediada no processo de formação dos conceitos científicos de fotossíntese e respiração celular em aulas de Biologia. Investigações em Ensino de Ciências. 21(2), 121-136. Recuperado de https://www.if.ufrgs.br/cref/ojs/ index.php/ienci/article/viewFile/325/210.

Wertsch, J. V. (1991). Voices of the mind: a sociocultural approach to mediated action. Cambridge, Massachusetts: Harvard University Press.

Wertsch, J. V. (1999). La mente en acción. Buenos Aires: Aique.

Wertsch, J. V. (1998). A necessidade da ação na pesquisa sociocultural. In J. V. Wertsch, P. Del Río, \& A. Alvarez (Orgs.). Estudos socioculturais da mente. (pp. 56-71). Porto Alegre: Artmed. 
Maria Margareth Cancian Roldi

(단.//orcid.org/0000-0002-8359-7433

Instituto Federal do Espírito Santo

Programa de Pós-Graduação em Educação em Ciências e Matemática Vitória, Espírito Santo, Brasil margacroldi@gmail.com

\section{Mirian do Amaral Jonis Silva}

${ }^{\circ}$ http://orcid.org/0000-0002-3838-8798

Universidade Federal do Espírito Santo

Programa de Pós-Graduação em Educação em Ciências e Matemática - IFES

Vitória, Espírito Santo, Brasil mirianjonis67@gmail.com

\section{Patricia Silveira da Silva Trazzi}

${ }^{10}$ http://orcid.org/0000-0003-0474-8588

Universidade Federal do Espírito Santo

Programa de Pós-Graduação Mestrado Profissional em Educação - UFES Vitória, Espírito Santo, Brasil patriciatrazzi.ufes@gmail.com

Submetido em 31 de Janeiro de 2018

Aceito em 18 de Setembro de 2018

Publicado em 15 de Dezembro de 2018 